\title{
Impact of Engineering Curricula and Student Programming on STEM Atti- tudes among Middle and High School Students (Evaluation)
}

\section{Dr. Jennifer B. Listman, New York University}

Dr. Jennifer Listman is the Assistant Director, Program Development and Evaluation, Center for K12 STEM Education, New York University Polytechnic School of Engineering. As the Center's resident research scientist, she conducts and publishes assessments and outcomes evaluations of Center programs for stewardship, research, and development purposes. Dr. Listman received her B.A. in Biology from the University of Pennsylvania in 1991 and her PhD in Anthropological Genetics from New York University in 2009. She conducted research on human evolutionary and migratory history in South East Asian populations and Jewish populations using genomic data and carried out collection of saliva samples as a DNA source from over 500 individuals in rural Thailand, to create a DNA resource of six ethnic populations. In addition, while Associate Research Scientist at Yale University School of Medicine, she conducted research on the evolutionary history of genes involved in alcohol metabolism and substance abuse. She has been awarded grants from the National Institutes of Health, National Science Foundation, and the Wenner Gren Foundation for Anthropological Research.

\section{Dr. Vikram Kapila, New York University}

Vikram Kapila is a Professor of Mechanical Engineering at NYU Tandon School of Engineering (NYU Tandon), where he directs a Mechatronics and Control Laboratory, a Research Experience for Teachers Site in Mechatronics and Entrepreneurship, a GK-12 Fellows project, and a DR K-12 research project, all funded by NSF. He has held visiting positions with the Air Force Research Laboratories in Dayton, $\mathrm{OH}$. His research interests include K-12 STEM education, mechatronics, robotics, and control system technology. Under Research Experience for Teachers Site and GK-12 Fellows programs, funded by NSF, and the Central Brooklyn STEM Initiative (CBSI), funded by six philanthropic foundations, he has conducted significant K-12 education, training, mentoring, and outreach activities to integrate engineering concepts in science classrooms and labs of dozens of New York City public schools. He received NYU Tandon's 2002, 2008, 2011, and 2014 Jacobs Excellence in Education Award, 2002 Jacobs Innovation Grant, 2003 Distinguished Teacher Award, and 2012 Inaugural Distinguished Award for Excellence in the category Inspiration through Leadership. Moreover, he is a recipient of 2014-2015 University Distinguished Teaching Award at NYU. In 2004, he was selected for a three-year term as a Senior Faculty Fellow of NYU Tandon's Othmer Institute for Interdisciplinary Studies. His scholarly activities have included 3 edited books, 8 chapters in edited books, 1 book review, 55 journal articles, and 126 conference papers. He has mentored 1 B.S., 17 M.S., and 4 Ph.D. thesis students; 31 undergraduate research students and 11 undergraduate senior design project teams; over $300 \mathrm{~K}-12$ teachers and 100 high school student researchers; and 18 undergraduate GK-12 Fellows and 60 graduate GK-12 Fellows. Moreover, he directs K-12 education, training, mentoring, and outreach programs that enrich the STEM education of over 1,500 students annually. 


\section{Impact of Engineering Curricula and Student Programming on STEM Attitudes among Middle and High School Students- Evaluation}

\section{Background}

Ajzen and Fishbein's ${ }^{1}$ theory of reasoned action describes a relationship between attitude, intention, and behavior; behavior is a result of intention and intention is a result of attitude towards the behavior combined with beliefs about how others will judge the behavior. Within this context, both individual student and overall classroom attitude towards science, technology, engineering, and math (STEM) disciplines and their content can affect student behaviors of engagement, performance, and persistence in STEM subjects and subsequent choice of a STEM career. Thus, creating a positive attitude towards STEM, overall, is a goal of STEM education. Interventions can be evaluated not only for their effect on STEM content learning, but also for their effect on student attitudes ${ }^{2}$ which can have longer-term effects on student career choice. Klopfer ${ }^{3}$ described six categories of attitudes relevant to science education goals: attitudes towards science and scientists, attitude towards inquiry, adoption of scientific attitudes like curiosity and open-mindedness, enjoyment of science learning experiences, interest in science apart from learning experiences, and interest in a career in science.

The 2000 report of the National Commission on Mathematics and Science Teaching for the $21^{\text {st }}$ Century, Before it's Too Late, ${ }^{4}$ noted the U.S.'s failure to "capture the interest of our youth for scientific and mathematical ideas" and its economic, social, and national security implications. In an effort to improve STEM education for local K-12 students, contribute to K-12 STEM education best practices, and attract a larger and more diverse pool of students to pursue higher STEM education, New York University Tandon School of Engineering (NYU Tandon) has developed engaging, hands-on curricula based on two engineering-based tracks: robotics and smart cities. These curricula have been applied through NYU Tandon's faculty and students to both direct K-12 student services such as summer programs and K-12 STEM teacher professional development (PD). While previous research has shown hands-on engineering-based teaching and learning to have a positive impact on STEM attitudes, ${ }^{5,6}$ we conducted an evaluation of student attitudes towards STEM both before and after their participation in an engineering-based summer STEM learning experience to evaluate our methods and curricula. In the spirit of promoting "Doing with Understanding,"7 our curricula were designed to provide students with the opportunity to learn while being creative, a sense of purpose in their learning, and a learning process that results in a "product" or result in which they could take pride. 


\section{Description of Summer Program}

In summer 2015, NYU Tandon provided 323 students with multi-week direct services following on-campus PD for 30 public school teachers using engineering-based robotics and smart cities curricula. Goals were to provide hands-on, standards-aligned STEM learning to underserved students and increase student interest in STEM learning.

\subsection{Teacher Professional Development}

NYU Tandon's students and faculty have developed lessons and activities for the two curricular tracks over the past decade under public and philanthropic support for K-12 STEM education projects. All lessons are developed through design-based research ${ }^{8-11}$ (DBR) within the framework of problem-based learning ${ }^{12-16}$ (PBL) using engineering challenges. Under faculty supervision, 12 graduate students modified and refined existing lessons and activities for middle and high school students and then conducted two week summer training for over 40 undergraduate and graduate NYU Tandon and NYU College of Arts and Science STEMmajor students who would deliver these curricula to teachers and students.

Thirty middle and high school teachers then attended a three-day training on the university campus, during which graduate students provided them with lectures paired with hands-on activities for one of the two engineering-based curricular tracks. For training, teachers were paired with an undergraduate or graduate student, who had completed the two-week training, to work alongside them and serve as the co-teacher once classroom activities began for the middle and high school students. Training for both tracks included basic use of microcontrollers and circuitry, sensors, programming, and data collection.

\subsection{Curricula}

Curricula have been aligned with several elements of the Next Generation Science Standards ${ }^{17}$ (NGSS) and the Common Core State Standards for Math ${ }^{18}$ (CCSSM), to facilitate the adoption of developed lessons by teachers and administrators. Through a DBR process we iteratively refined curricula with participant feedback to optimize lessons according to learning environment and participant needs. The lessons have been created to present STEM content as interconnected rather than in parallel and in engineering contexts relevant to students' lives.

In PBL contexts, ${ }^{12-16}$ students learn both content and thinking strategy through facilitated problem solving. In contrast to $\mathrm{PBL},{ }^{12-15}$ conventional passive and compartmentalized learning methods do not support students to become future STEM innovators through cultivation of skills such as intrinsic goal orientation, critical thinking, attitude towards 
learning, problem solving, and self- regulation. ${ }^{15,16}$ PBL interventions have been shown to be effective in increasing STEM content knowledge in secondary school students, ${ }^{19}$ particularly when the problem to be solved or artifact to be designed is not the final goal but a framework for learning related material. ${ }^{20}$

The robotics and smart cities curricula provide middle and high school students with an opportunity to experience engineering design as a model for problem solving while working with tools used by engineers such as microcontrollers, circuit components, programming, and sensors. Through hands-on activities, they learn STEM content, technology, and engineering skills. The smart cities curriculum includes four integrated themes: energy, urban infrastructure, transportation, and wireless communications. Students collaborate in groups to develop strategies to complete missions in the hands-on exercises in the robotics curriculum. These lessons have been developed to help students visualize science and math concepts, which are typically difficult or abstract. Since many STEM principles are inherently incorporated into each engineering design challenge or mission, they can also illustrate connections between the different STEM disciplines and their applications. Involving the undergraduate and graduate engineering students, directly, with the classroom teaching, allows them to serve as STEM professional role-models for the middle and high school students.

\subsection{Participants}

Student participants were entering $8^{\text {th }}$ or $11^{\text {th }}$ grade and were chosen by the New York City Department of Education (NYC DoE) via lottery. Students were not required to have a strong interest in STEM subjects. Retention rate of students was $76 \%$. Both pre and post program, the cohort remained $42 \%$ female; there was no gender difference in dropout rate. Services were provided at five public schools such that each of the five NYC boroughs had a location, with students drawn from the entire borough for a given school. District teachers applied for summer positions and were selected by the NYC DoE. Not all teachers were math or science certified; the cohort included humanities teachers, as well. After a three-day intensive PD at the university, teacher/engineering student pairs co-taught either robotics or smart cities engineering-based curricula, four days/week, six hours/day, for five weeks.

Table 1: Student participants by gender and program.

\begin{tabular}{|l|r|r|}
\hline Student Category & $N$ Pre & $N$ Post \\
\hline Total & 323 & 245 \\
\hline Male & 188 & 142 \\
\hline Female & 134 & 103 \\
\hline Smart Cities & 180 & 140 \\
\hline Robotics & 140 & 105 \\
\hline
\end{tabular}




\section{Survey Data}

The project was assessed using student responses to a ten item anonymous paper survey, pre $(\mathrm{N}=323)$ and post $(\mathrm{N}=245)$ project. Items were adapted from NSF-funded STEM attitudes and perceptions surveys, e.g., the STEM Career Interest Questionnaire ${ }^{21}$ and the SWEPT Student Pre-Attitude Survey. ${ }^{22}$ The original surveys were designed to examine students' attitudes about science and mathematics, views about STEM career opportunities and education, perceptions of the importance of a career in science, and supportive environment for pursuing a career in science. The following 10 items were used such that they fit on one single-sided page, to maximize the number of completed surveys.

Ql: I would like to have a career in a science, technology, engineering, or math (STEM) field.

Q2: My family has encouraged me to learn more STEM.

Q3: I will attend a 4-year college and major in a STEM field.

Q4: People would respect me if I have a STEM-related job, when I'm an adult.

Q5: Having a STEM-related career would be difficult.

Q6: Science, math, or computer programming classes make me feel nervous.

Q7: I usually understand what is going on in my STEM classes.

Q8: My family expects me to complete a 4-year college.

Q9: My family asks me about what I'm learning in school.

Q10: I know someone with a STEM related job who encourages me to pursue a STEM career, too.

It has been shown that children do not respond well to numerical Likert scales, rather, phrases

which can be later re-coded to numbers are more robust. ${ }^{23}$ Students were able to circle one of the following five responses, which were re-coded for data analysis, to correspond to values 1 through 5.

YES!

Pretty much

Idon't know (3)

Not really

NO!

In addition to assuming unmatched samples, all data were included and some survey answers were left blank, such that the pre sample size is larger than the post sample size and sample sizes differ slightly among questions. Grade $\left(7^{\text {th }}\right.$ vs. $\left.10^{\text {th }}\right)$ was not used as a variable in any analysis. 


\section{Analysis and Results}

A Kolmogorov-Smirnov test ${ }^{24}$ (KS-test) was performed for each question 1-10 to identify significant differences in pre vs. post means after recoding responses as discrete values from 1 to 5. Gender, program, and grade differences were not taken into account at this stage. The KS-test tries to determine if two datasets differ significantly in shape of their distributions, rather than difference in mean. The KS-test makes no assumption about the distribution of data, so, in contrast to a t-test, it is appropriate for non-normally distributed data. KS tests (Table 1), not corrected for multiple testing, showed significance $(p=0.007)$ only for Q7 "I usually understand what is going on in my STEM classes" and suggestive significance $(p=0.078)$ for Ql "I would like to have a career in a science, technology, engineering, or math (STEM) field.” All other statements showed non-significant differences pre/post-program.

Table 2: Kolmogorov-Smirnov tests of pre vs. post responses for questions 1 through 10.

\begin{tabular}{|l|r|r|r|r|r|r|r|r|r|r|}
\hline & Q1 & Q2 & Q3 & Q4 & Q5 & Q6 & Q7 & Q8 & Q9 & Q10 \\
\hline$p$-value & $\mathbf{0 . 0 7 8}$ & 0.447 & 0.961 & 0.682 & 0.446 & 0.999 & $\mathbf{0 . 0 0 7}$ & 0.337 & 0.800 & 0.155 \\
\hline Pre Average & 2.278 & 2.237 & 2.534 & 2.475 & 2.872 & 3.906 & 2.118 & 1.794 & 1.934 & 3.288 \\
\hline Pre $N$ & 323 & 322 & 320 & 323 & 321 & 322 & 319 & 322 & 321 & 323 \\
\hline Post Average & 2.086 & 2.193 & 2.444 & 2.360 & 2.778 & 3.833 & 1.824 & 1.542 & 1.810 & 2.936 \\
\hline Post $N$ & 245 & 245 & 244 & 245 & 245 & 245 & 245 & 242 & 243 & 245 \\
\hline Change & 0.192 & 0.045 & 0.090 & 0.115 & 0.094 & 0.073 & 0.294 & 0.253 & 0.124 & 0.351 \\
\hline
\end{tabular}

A nonparametric randomization test with multiple linear regression ${ }^{25}$ was used to assess statistical significance; for normally-distributed data this test and Three-way Analysis of Variance $^{26}$ (ANOVA) compute identical $p$-values, but unlike ANOVA this test is appropriate for samples from any statistical distribution. This test was used to tease apart factor-specific effects, not detected by the KS test, in addition to interaction effects between factors (Table 3). Both genders showed the same dropout rate, so the data did not require correction for this factor. The data (each participant's 1-5 response to each question) were fit with multiple linear regression; the columns of the regression matrix coded for each of the main effects (male vs female, pre vs post program, smart cities vs robotics) and each interaction (3 two-way interactions and 1 threeway interaction). We computed the variance accounted for by each main effect and each interaction (i.e., each regressor). We then obtained null distributions for the variance accounted for by each main effect and each interaction. These null distributions were computed by repeating the regression 10,000 times, each time after randomly shuffling the data. ${ }^{27}$ We compared the results of the regression using the original unshuffled data with the null distributions to obtain $p$ values for each main effect and each interaction. 
Table 3: Randomized multiple linear regression analysis $p$-values of pre vs. post responses for questions 1 through 10.

\begin{tabular}{|r|r|r|r|r|r|r|c|}
\hline Question & \multicolumn{1}{|c|}{ Status } & \multicolumn{1}{c|}{ Gender } & \multicolumn{1}{c|}{ Program } & \multicolumn{1}{c|}{$\begin{array}{c}\text { Status } \times \\
\text { Gender }\end{array}$} & \multicolumn{1}{c|}{$\begin{array}{c}\text { Status } \times \\
\text { Program }\end{array}$} & $\begin{array}{c}\text { Gender } \times \\
\text { Program }\end{array}$ & $\begin{array}{c}3 \\
\text { Way }\end{array}$ \\
\hline 1 & 0.097 & 0.057 & 0.996 & 0.083 & 0.253 & 0.784 & 0.086 \\
\hline 2 & 0.621 & $\mathbf{0 . 0 1 0}$ & 0.951 & 0.159 & 0.072 & 0.298 & 0.939 \\
\hline 3 & 0.527 & 0.470 & 0.938 & 0.503 & 0.799 & 0.756 & 0.258 \\
\hline 4 & 0.278 & 0.994 & 0.945 & 0.228 & 0.500 & 0.714 & 0.148 \\
\hline 5 & 0.406 & 0.599 & 0.583 & 0.684 & 0.746 & 0.686 & 0.422 \\
\hline 6 & 0.682 & 0.121 & 0.262 & 0.457 & 0.115 & $\mathbf{0 . 0 2 4}$ & 0.909 \\
\hline 7 & $\mathbf{0 . 0 0 1}$ & 0.097 & 0.373 & 0.130 & 0.468 & 0.455 & 0.747 \\
\hline 8 & $\mathbf{0 . 0 0 4}$ & $\mathbf{0 . 0 0 1}$ & 0.471 & 0.280 & $\mathbf{0 . 0 1 4}$ & 0.192 & 0.233 \\
\hline 9 & 0.209 & 0.556 & 0.435 & 0.487 & 0.404 & 0.135 & 0.130 \\
\hline 10 & $\mathbf{0 . 0 4 0}$ & 0.150 & 0.827 & 0.738 & 0.114 & 0.736 & 0.669 \\
\hline
\end{tabular}

The following three statements showed significant positive change $(p<0.05)$, without correction for multiple testing, associated with program participation status pre vs. post:

Q7: I usually understand what is going on in my STEM classes.

Q8: My family expects me to complete a 4-year college.

Q10: I know someone with a STEM related job who encourages me to pursue a STEM career, too.

Responses to some statements were significantly correlated with gender prior to program participation. Boys were significantly more likely than girls to affirm the statement Q2 "My family has encouraged me to learn more STEM" and girls were significantly more likely to affirm the statement Q8 "My family expects me to complete a 4 year college." While there was a significant increase, overall for Q8 pre vs. post, the change was more drastic for girls and girls both began and ended the program with more positive ratings for this statement.

Only two statements showed significant interaction effects. Q8: "My family expects me to complete a 4-year college" showed a significant interaction for status $\times$ program; specifically, while, on average, after program participation, both genders were more likely to report that their family expects them to complete a 4 year college, the change was greater for those students in the robotics track. Q6: "Science, math, or computer programming classes make me feel nervous" showed a significant interaction for gender $\times$ program; girls were more likely to report that STEM classes made them feel nervous and this was more likely for those in the smart cities 
track, however, this was true both pre and post program participation.

\section{Discussion and Conclusions}

Results support previous work ${ }^{5,6}$ indicating that a hands-on STEM curriculum provided through engineering challenges improves average attitudes and perceptions towards STEM education and STEM careers among K-12 students. Responses were significantly associated with gender, preprogram, for items describing messages to students from their families regarding educational expectations; boys are less likely to believe that they are expected to attend college and girls are less likely to believe that they are expected to prioritize STEM classes. Roots of these genderspecific under-expectations on the part of students' families and potential solutions have been explored in STEM education research, elsewhere. ${ }^{28}$ While results were not corrected for multiple testing, they are useful for identifying further research questions. We plan to gather additional data in subsequent years, including teacher questionnaire responses, to further investigate the effects of our challenge-based engineering programs and specific factors within our programs on student STEM attitudes.

\section{Acknowledgements}

This work is funded in part by the New York City Department of Education and by the Microsoft Corporation via The Fund for Public Schools. We thank NYC DoE Chancellor, Carmen Fariña, for supporting our work with NYC teachers and students. David Heeger provided MATLAB code and simulations used as part of the statistical analyses.

\section{References}

1. Ajzen, I. and Fishbein, M. 1980. Understanding Attitudes and Predicting Social Behavior. Englewood Cliffs, NJ: Prentice Hall.

2. Osborne, J., Simon, S., and Collins, S. 2003. “Attitudes towards science: A review of the literature and its implications.” Int. Journal of Science Education 25(9): 1049-1079.

3. Klopfer, L.E. 1971. "Evaluation of learning in science.” In Handbook on Summative and Formative Evaluation of Student Learning. B.S. Bloom, J.T. Hastings, and G.F. Madaus (Eds.), New York, NY: McGraw-Hill.

4. NCMST. 2000. Before it's too Late: A Report to the Nation from the National Commission on Mathematics and Science Teaching for the 21st Century. Education Publications Center.

5. Cantrell, P., et al. 2006. "The effects of engineering modules on student learning in middle school science classrooms.” Journal of Engineering Education 95(4): 301.

6. Barker, B.S. and Ansorge, J. 2007. "Robotics as means to increase achievement scores in an informal learning 
environment.” Journal of Research on Technology in Education 39(3): 229-243.

7. Barron, B.J.S., et al. 1998. "Doing with understanding: Lessons from research on problem-and project-based learning.” Journal of the Learning Sciences 7(3-4): 271-311.

8. Brown, A.L. 1992. "Design experiments: Theoretical and methodological challenges in creating complex interventions in classroom settings.” The Journal of the Learning Sciences 2(2): 141-178.

9. Kelly, A. 2004. "Design research in education: Yes, but is it methodological?” The Journal of the Learning Sciences 13(1): 115-128.

10. Fishman , B.J., et al. 2013. "Design-based implementation research: An emerging model for transforming the relationship of research and practice.” Design-based Implementation Research: Theories, Methods, and Exemplars. National Society for the Study of Education Yearbook 112(2): 136-156.

11. Zaritsky, R., et al. 2003. "Clinical design sciences: A view from sister design efforts.” Educational Researcher 32(1): 32-34.

12. Blumenfeld, P.C., 1991. "Motivating project-based learning: Sustaining the doing, supporting the learning." Educational Psychologist 26(3/4): 368-398.

13. Jayarao, A. 2014. "Engaging young minds to be tomorrow's innovators." In Einstein Fellows: Best Practices in STEM Education. T. Spuck and L. Jenkins (Eds.), New York, NY: Peter Lang: 158-181.

14. Larmer, J. and Mergendoller, J.R. 2010. "Seven essentials for project-based learning.” Educational Leadership 68(1): 34-37.

15. Spuck, T. 2014. "Putting the 'authenticity’ into science learning." In Einstein Fellows: Best Practices in STEM Education. T. Spuck and L. Jenkins (eds.), New York, NY: Peter Lang, 118-157.

16. Sungur, S. and Tekkaya, C. 2006. "Effects of problem-based learning and traditional instruction on selfregulated learning.” J. Education Research 99: 307-320.

17. Next Generation Science Standards (NGSS): For States, By States. 2013. Washington, DC: The National Academies Press. Online: http://www.nextgenscience.org/.

18. Common Core Standards for Mathematics. Common Core Standards Initiative. (2010). Online: http://www.corestandards.org/assets/CCSSI Math\%20Standards.pdf.

19. Petre, M. and Price, B. 2004. "Using robotics to motivate 'back door' learning." Education and Information Technologies 9(2): 147-158.

20. Benitti, F.B.V. 2012. "Exploring the educational potential of robotics in schools: A systematic review." Computers \& Education 58(3): 978-988.

21. Tyler-Wood, T., Knezek, G., and Christensen, R. 2010. "Instruments for assessing interest in STEM content and careers.” Journal of Technology and Teacher Education 18(2): 345-368.

22. Dubner, J., et al. 2001. "Evaluating science research experience for teachers programs and their effects on student interest and academic performance: A preliminary report of an ongoing collaborative study by eight programs.” MRS Proceedings Cambridge University Press 684(1).

23. Mellor, D. and Moore, K.A. 2014. "The use of Likert scales with children.” Journal of Pediatric Psychology 39(3): 369-379.

24. Kirkman, T.W. 1996. Statistics to Use. http://www.physics.csbsju.edu/stats/. (Accessed January 23, 2016)

25. Efron, B. and R. J. Tibshirani (1993). An Introduction to the Bootstrap. London: Chapman \& Hall/CRC Press.

26. Cohen, B.H. 2008. Explaining Psychological Statistics. John Wiley and Sons. 
27. Shasha, D. and Wilson, M. (2008). Statistics is Easy! Morgan \& Claypool.

28. Tenenbaum, H.R. and Leaper, C. 2003. "Parent-child conversations about science: The socialization of gender inequities?.” Developmental Psychology 39(1): 34. 